\title{
High Prevalence of Spinal Cord Cavernous Malformations in the Familial Cerebral Cavernous Malformations Type 1 Cohort
}

(D) M.C. Mabray, (D). Starcevich, (D). Hallstrom, (D). Robinson, (D). Bartlett, (D). Nelson, (D) A. Zafar,

(D) H. Kim, (D) Lorrison, and (D)B.L. Hart

\begin{abstract}
BACKGROUND AND PURPOSE: Cavernous malformations occur most often in the brain but can occur in the spinal cord. Small studies of patients with familial cerebral cavernous malformations suggested a prevalence of spinal cord cavernous malformations of $20 \%-42 \%$. We aimed to review our familial cohort and prospectively estimate the prevalence of spinal cord cavernous malformations.
\end{abstract}

MATERIALS AND METHODS: We initially reviewed our familial cerebral cavernous malformations cohort for spinal cord cavernous malformations and reviewed clinical spine MR imaging examinations for sequence sensitivity. We then prospectively performed research MR imaging of the spinal cord in 29 patients from the familial cohort to estimate the prevalence.

RESULTS: Gradient-based sequences identified the most spinal cord cavernous malformations on clinical MR images, forming the basis for developing our screening MR imaging. Screening spinal cord MR imaging demonstrated a prevalence of $72.4 \%$, and a positive correlation with patient age and number of cerebral cavernous malformations.

CONCLUSIONS: Spinal cord cavernous malformations occur commonly in the familial cerebral cavernous malformation population. Gradient-based sequences are the most sensitive and should be used when spinal cord cavernous malformations are suspected. This study establishes the prevalence in the familial population at around $70 \%$ and supports the idea that this condition is a progressive systemic disease that affects the entire central nervous system.

ABBREVIATIONS: $\mathrm{CM}=$ cavernous malformation; $\mathrm{CCM}=$ cerebral cavernous malformation; SCCM = spinal cord cavernous malformation; MEDIC = MultiEcho Data Image Combination

avernous malformations (CMs) are dilated capillary-type lowflow vascular malformations, which are prone to repeated

Received February 27, 2020; accepted after revision March 19.

From the Departments of Radiology (M.C.M., J.S., J.H., B.L.H.) and Neurology (M.R. M.B., A.Z., L.M.), University of New Mexico Health Sciences Center, University of New Mexico, Albuquerque, New Mexico; and Departments of Anesthesia and Perioperative Care, Center for Cerebrovascular Research (J.N., H.K.), and Epidemiology and Biostatistics (H.K.), University of California San Francisco, San Francisco, California.

Grant funding from the National Institute of Health-National Institute of Neurological Disorders and Stroke (grant number U54 NS065705), Radiology Department Seed Grant, and the Cody Unser First Step Foundation.

Portions of this research previously presented at: Annual Meetings of the American Society of Neuroradiology Annual Meeting, May 23-26, 2016, Washington, DC; American Society of Spine Radiology Annual Symposium, February 18-21, 2016, Bonita Springs, Florida; Western Neuroradiological Society Annual Meeting October 11-14, 2018, Dana Point, California; and Annual Angioma Alliance Cerebral Cavernous Malformations Scientific Meeting, November 8-9, 2018, Silver Spring, Maryland.

Please address correspondence to Marc C. Mabray, MD, Department of Radiology, University of New Mexico, MSC 10 5530, 1 University of New Mexico, Albuquerque, NM, 87131; email: mamabray@salud.unm.edu

- Indicates open access to non-subscribers at www.ajnr.org

http://dx.doi.org/10.3174/ajnr.A6584 hemorrhage and growth over time. ${ }^{1-5}$ Cerebral cavernous malformations (CCMs) occur with a prevalence of about $0.5 \%$ in the general population. ${ }^{1,2,6}$ About $80 \%$ of CCMs are sporadic, solitary, and often closely associated with a developmental venous anomaly, and about $20 \%$ of CCMs are familial/syndromic. ${ }^{1,2}$ Mutations that lead to familial CCM syndrome can occur in 3 genes (CCM1 or KRIT1, CCM2, and CCM3 or PDCD10) with an autosomal dominant transmission. ${ }^{2,4,7-9}$ There is a particularly high prevalence of familial CCM syndrome (CCM1-common Hispanic mutation) in southwest North America due to a founder effect in early Hispanic settlers. $^{1,2,4,9}$ Spinal cord cavernous malformations (SCCMs) are less common than CCMs and have been considered rare, with relatively less attention in the CCM literature and most reported cases being sporadic nonfamilial SCCMs. ${ }^{10-19}$ A 2009 report on a single Italian family with familial CCM found SCCMs in 5 of 12 patients (41.7\%), 2 of which were discovered clinically and 3 of which were discovered with screening MR imaging (3 of 6 screened patients had SCCMs). ${ }^{20}$ An additional 2017 report on 13 patients with familial CCM found upper SCCMs in 3 patients (23.1\%). ${ }^{21}$ Given these estimates of SCCM prevalence in small sample sizes, and what we 


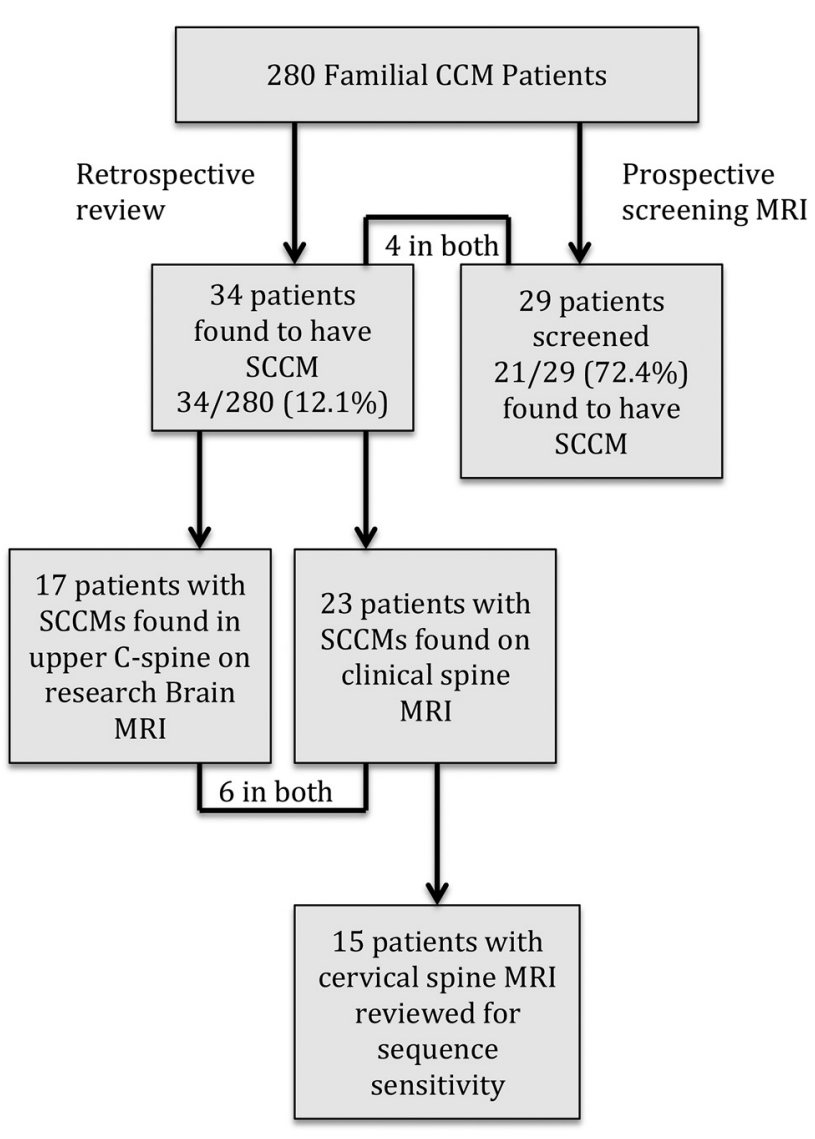

FIG 1. Flow chart of the study.

had been encountering in our cohort, we aimed to systematically study SCCMs in our familial CCM1 cohort. We initially reviewed our familial CCM cohort retrospectively and evaluated the sensitivity of various MR imaging sequences for detecting SCCMs; we then prospectively imaged the spinal cord in 29 patients to estimate the prevalence of SCCMs in familial CCM. We expected to find a high prevalence of SCCMs in this patient population and that the number of SCCMs would positively correlate with the number of brain CCMs and age, supporting the idea of familial CCM as a progressive systemic disease that affects the entire central nervous system.

\section{MATERIALS AND METHODS}

The study was institutional review board compliant, and all subjects gave informed consent to participate. An overall outline of the study is demonstrated in Fig 1.

\section{Initial Retrospective Review}

Our research cohort consisted of 280 patients with familial CCM syndrome participating in a prospective longitudinal study. This cohort consists of patients with the CCM1 common Hispanic mutation. Patients must have a genetic diagnosis of CCM, or meet 2 of the 3 criteria of a clinical diagnosis of CCM, have evidence of multiple CMs on MR imaging, or a family member with a diagnosis of CCM1. We initially retrospectively reviewed the records of patients in this research cohort to identify patients with known SCCMs as an estimate of the lower bound of prevalence in our cohort.

\section{MR Imaging Sequence Sensitivity}

Based on this initial retrospective analysis, we set out to determine the sensitivity of sequences to determine our protocol for screening the spinal cord for SCCMs. Fifteen of the patients had clinically performed cervical spine MR images available, for which the number of SCCMs visible on each sequence was analyzed. Sequences consisted of sagittal T1 TSE, sagittal T2 TSE, and axial T2 Multi-Echo Data Image Combination (MEDIC; Siemens). A sagittal 3D MEDIC was also performed in 8 of the patients. SWI was performed in 2 cases, but proved significantly limited by artifact and was not analyzed for sequence sensitivity. Anonymized and randomized MR imaging sequences were presented to 2 attending neuroradiologists, who separately recorded the number of SCCMs seen on each individual sequence. This was followed by a consensus review to agree upon the number of SCCMs detected for each sequence. The proportion of SCCMs detected for each sequence was calculated compared with the total number detected across all sequences, and the sensitivity of detecting SCCMs was calculated relative to the total number of SCCMs.

\section{Screening Spinal Cord MR Imaging}

After the initial review of our cohort and using what we had learned about sequence sensitivity, we prospectively screened the spinal cord with MR imaging in 29 of the patients in the study. We offered research MR imaging of the cervical and thoracic spine to consecutive patients who were returning for research brain MR imaging; 30 patients were scheduled for cervical and thoracic spine MR imaging and 29 patients completed the MR imaging. Four patients in the prospective screening group were also in the group of 34 patients found to have SCCMs on retrospective review. Research MR imaging was performed on a $3 \mathrm{~T}$ Skyra scanner (Siemens) and was set up as sagittal T1 TSE (TE, $10 \mathrm{~ms}$; TR, 647), sagittal T2 TSE (TE, $110 \mathrm{~ms}$; TR, $2500 \mathrm{~ms}$ ), and sagittal 3D MEDIC (TE, $11 \mathrm{~ms}$; TR, $28 \mathrm{~ms}$ ) performed in 2 segments (cervical spine through upper thoracic spine with a field of view of $280 \mathrm{~mm}$, and upper thoracic spine through the conus with a field of view of $340 \mathrm{~mm}$ ) (Fig 2). The 3D MEDIC sequence was reformatted into 1-mm axial images for review.

An attending neuroradiologist reviewed the research MR imaging examinations, and SCCMs were characterized by number, size, and imaging appearance. We also recorded and characterized any vertebral intraosseous vascular malformations on screening MR imaging as these have recently been reported to be of high prevalence in patients with $\mathrm{CCM}^{22}$ We tested whether SCCM counts were associated with age and total brain CCM count by using the Spearman rank correlation.

\section{RESULTS}

In the overall cohort study of 280 patients, $61.4 \%$ of the patients enrolled were female, and $72.4 \%$ of the spine MR imaging screened patients were female, which was not statistically significantly different $(P=.14)$. The mean age for the 280 patients enrolled in the overall cohort study was 39.0 years (SD 19.7); the mean age for the 29 patients prospectively screened with spine MR imaging was higher at 47.4 years $(\mathrm{SD} 18.4)(P=.009)$.

AJNR Am J Neuroradiol 41:1126-30 Jun 2020 www.ajnr.org 


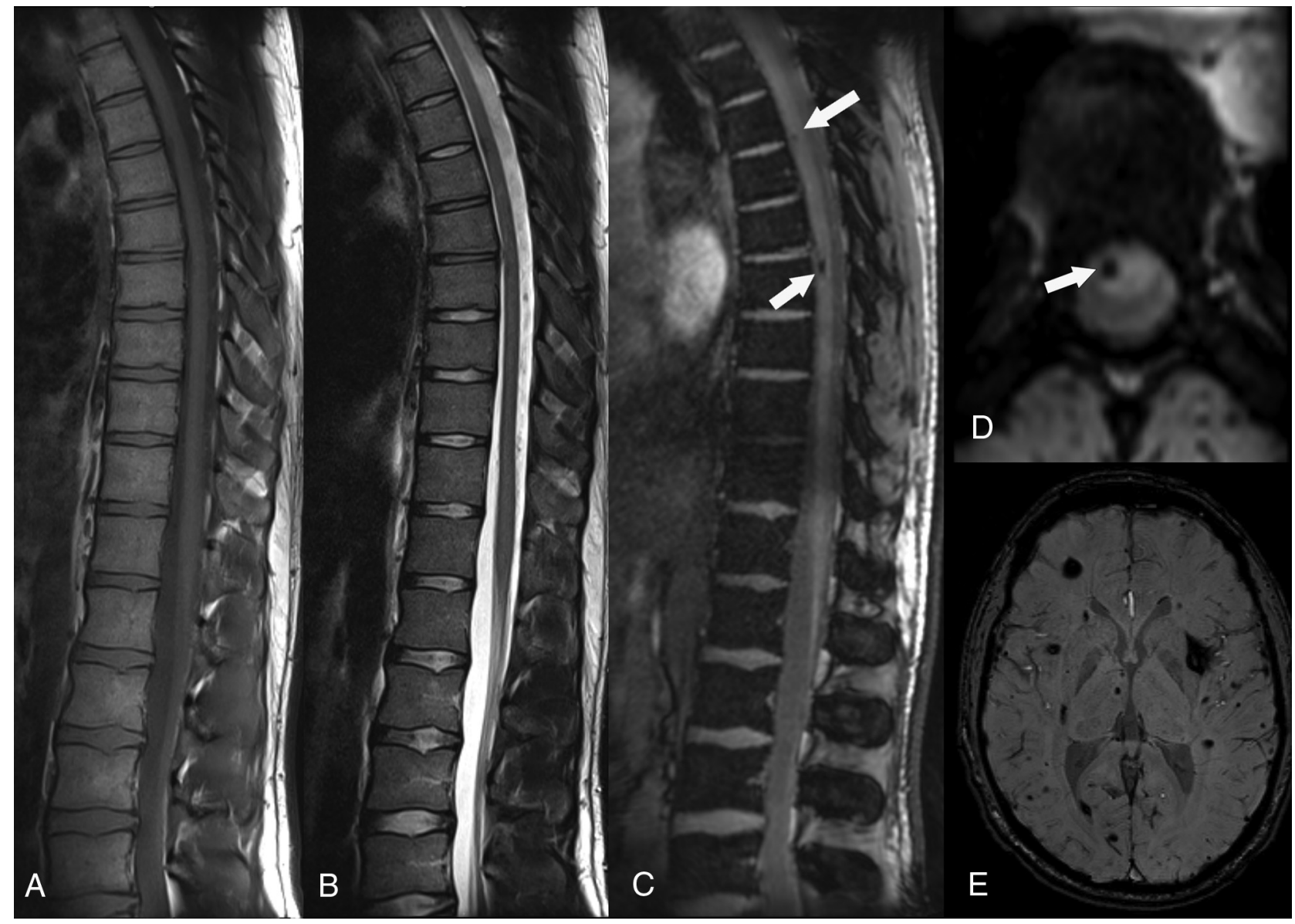

FIG 2. Sagittal T1 TSE (A), sagittal T2 TSE (B), sagittal 3D MEDIC (C), and axial reformat of the 3D MEDIC (D), from spinal cord screening research MR imaging and corresponding SWI from brain research MR imaging done on the same day (E). On sagittal 3D MEDIC (C), arrowsdenote small SCCM. D, Axial reformat shows small CM in the right aspect of the spinal cord (arrow), corresponding to the more inferior of the 2 lesions. $E, \mathrm{SWI}$ of the brain shows multiple CMs which are typical of familial CCM syndrome.

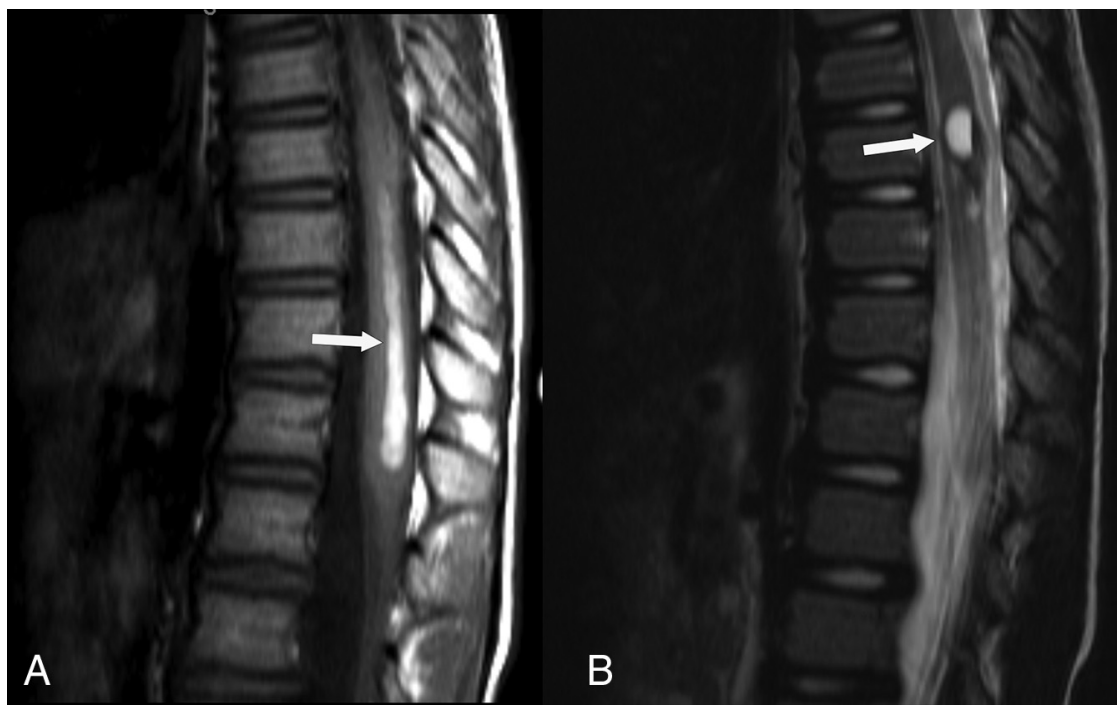

FIG 3. $A$, Sagittal TI TSE and sagittal T2 TSE (B), from clinical MR imaging of the thoracic spine demonstrates spinal cord hemorrhage from a SCCM. On sagittal TI TSE (A), there are T1 hyperintense blood products tracking down the thoracic spinal cord (arrow) toward the conus medularis. On sagittal T2 TSE (B), there are mixed-signal blood products (arrow) at the site of the spinal cord cavernous malformation.

\section{Initial Retrospective Review}

On retrospective review of the familial CCM cohort, we found that 34 patients (12.1\%; 95\% CI, 8.6\%-16.6\%) had SCCMs: 17 were identified in the upper cervical spinal cord on research brain MR imaging, and 23 were found on clinical spine MR imaging (6 in both groups). Seven of the 23 showed findings of acute spinal cord hemorrhage on MR imaging (Fig 3). Seven patients had surgery to remove the SCCM, 4 of whom had spinal cord hemorrhage. Nineteen patients were deemed to have clinical symptoms referable to the SCCM.

\section{MR Imaging Sequence Sensitivity on Clinical Cervical Spine MRI}

Some SCCMs were visible on routine TSE sequences, but gradient-based techniques were more sensitive for 
Table 1: Analysis of sequence sensitivity for SCCM, retrospectively performed on 15 clinically performed cervical spine MR imaging studies

\begin{tabular}{lcc}
\hline & $\begin{array}{c}\text { Number of SCCMs } \\
\text { Detected }\end{array}$ & $\begin{array}{c}\text { Sensitivity Relative to Total } \\
\text { Number of SCCMs }\end{array}$ \\
\hline Sagittal TI TSE & 3 of 21 & $14.3 \%(95 \% \mathrm{Cl}, 3.0 \%-36.3 \%)$ \\
Sagittal T2 TSE & 6 of 21 & $28.6 \%(95 \% \mathrm{Cl}, 11.2 \%-52.2 \%)$ \\
Axial T2 TSE & 5 of 21 & $23.8 \%(95 \% \mathrm{Cl}, 8.2 \%-47.2 \%)$ \\
Axial T2 MEDIC & 17 of 21 & $81.0 \%(95 \% \mathrm{Cl}, 58.1 \%-94.6 \%)$ \\
3D MEDIC & 8 of $8^{\mathrm{a}}$ & $100 \%(95 \% \mathrm{Cl}, 68.8 \%-100 \%)$ \\
\hline
\end{tabular}

${ }^{a} 3 D$ MEDIC sequence was performed on a subset of patients.

Table 2: Results of prospective screening MR imaging of the spinal cord

\begin{tabular}{|c|c|c|}
\hline & Prevalence & Lesions per Patient \\
\hline $\begin{array}{l}\text { Spinal cord cavernous } \\
\text { malformations }\end{array}$ & $21 / 2972.4 \%$ (95\% Cl, 52.8\%-87.3\%) & $\begin{array}{l}\text { Mean }=3.2(\text { SD 3.9) } \\
\text { Median }=2 \\
\text { Range }=0-17\end{array}$ \\
\hline $\begin{array}{c}\text { Cerebral cavernous } \\
\text { malformations }\end{array}$ & 29/29 100\% (95\% Cl, 90.2\%-100\%) & $\begin{array}{l}\text { Mean }=105.7(\text { SD 128.0) } \\
\text { Median }=53 \\
\text { Range }=4-584\end{array}$ \\
\hline $\begin{array}{l}\text { Vertebral osseous vascular } \\
\text { malformations }\end{array}$ & $20 / 2969.0 \%$ (95\% Cl, 49.2\%-84.7\%) & $\begin{array}{l}\text { Mean }=1.6(\text { SD 1.7) } \\
\text { Median }=1 \\
\text { Range }=0-7\end{array}$ \\
\hline
\end{tabular}

\section{DISCUSSION}

With prospective imaging to screen the spinal cord, we found SCCMs in 21 of 29 patients with familial CCM1, a prevalence of $72.4 \% \quad(95 \%$ CI, $52.8 \%-$ $87.3 \%)$. Prior reports of 5 of 12 patients (41.7\%, 3 discovered with screening MRI), and 3 of 13 patients (23.1\%) were higher than what was initially known in our cohort, but lower than what we found with screening MR imaging. $^{20,21}$ Our study establishes an estimated prevalence of SCCMs in the familial CCM1 population of approximately $70 \%$.

Our study demonstrates that SCCMs are indeed a common finding in patients with familial CCM and supports the idea of familial CCM syndrome as a progressive systemic disease that affects the entire central nervous system. We found an expected positive

detecting SCCMs (Table 1). Of the 15 patients with cervical spine MR imaging, we detected more of the 21 total SCCMs with the gradient-based MEDIC sequences than traditional T1 and T2 sequences (Table 1). Sagittal T1 TSE detected $14.3 \%$ (of total SCCMs), sagittal T2 TSE detected $28.6 \%$, axial T2 TSE detected $23.8 \%$, and axial T2 MEDIC detected $81.0 \%$ (including 4 of 8 SCCMs seen by 3D MEDIC) of the total SCCMs. 3D MEDIC, when performed, had detected the most SCCMs and had an advantage over 2D MEDIC in spatial resolution and permitted multiplanar reconstruction. Thus, 3D MEDIC was selected for use in our screening MR imaging of the spinal cord.

\section{Screening MR Imaging of the Spinal Cord}

In the prospective group of 29, the mean age was 46.3 (SD 18.8) and $21(72.4 \%)$ were female. We found SCCMs in 21 of 29 patients (72.4\%; 95\% CI, 52.8\%-87.3\%) screened with the dedicated research spinal cord MR imaging (Table 2). The mean number of SCCMs per patient was 3.2 (SD 3.9, median 2, range 0-17). SCCMs were small with a mean axial diameter of $2.5 \mathrm{~mm}$ (SD 1.3, median 2, range $1-8 \mathrm{~mm}$ ) (Fig 2) on the axial reformat of the $3 \mathrm{D}$ MEDIC. Only 2 of the larger SCCMs showed mixed T2 signal intensity (type II CMs), the rest showed only dark hemosiderin signal (type IV CMs). ${ }^{3}$ Only 20 of the 29 patients (69.0\%; $95 \%$ CI, $49.2 \%-84.7 \%)$ had any vertebral intraosseous vascular malformation; while 11 of the 29 (37.9\%; 95\% CI, 20.7\%$57.7 \%$ ) had an atypical (T1 hypointense) intraosseous vascular malformation, and 16 of the 29 (55.2\%; 95\% CI, 35.7\%$73.6 \%$ ) had a typical (T1 hyperintense) intraosseous vascular malformation (Table 2 ). There was a strong, positive correlation between number of SCCMs and age $(\rho=0.748, P<.001)$ and between number of SCCMs and number of brain CMs $(\rho=0.649, P<.001)$. There was not a statistically significant correlation between the number of SCCMs and intraosseous vascular malformations. correlation of number of SCCMs with both patient age and number of intracranial CCMs. We also found a high prevalence of vertebral intraosseous vascular malformations (69\%), including atypical (T1 hypointense) intraosseous vascular malformation in approximately $38 \%$ of the patients who underwent MR imaging screening, supporting the recent finding that these are common in patients with familial CCM. ${ }^{22}$

Many of the SCCMs that we found with screening were quite small (mean diameter of $2.52 \mathrm{~mm}$ ) and we would not expect them to currently alter patient management. SCCMs were not commonly clinically discovered in our larger cohort (23/280 patients, $8.2 \%)$, and presenting with spinal cord hemorrhage $(n=7)$ and being operated on for SCCM $(n=7)$ were even rarer in our cohort. Currently, there are no guidelines to suggest screening the spinal cord for SCCMs in patients with familial CCM; if that were performed, we would expect that many, mostly small, SCCMs would be found as was the case in this study. ${ }^{2}$

Gradient-based MEDIC sequences were found to be more sensitive to the detection of SCCMs compared with T1 and T2 sequences (which detected only $14.3-28.6 \%$ of the SCCMs compared with the MEDIC sequences). Additionally, 3D MEDIC was more sensitive for SCCM detection compared with 2D MEDIC, which detected only 4/8 SCCMs in patients with both $2 \mathrm{D}$ and 3D imaging. Many SCCMs were visible only as small foci of susceptibility, accounting for the limited visibility on $\mathrm{T} 2$ and $\mathrm{T} 1$ sequences. SWI, of proved superiority for detection of CMs in the brain as compared with T2 or GRE sequences, was limited in the spine by artifact. $^{23,24} 3 \mathrm{D}$ MEDIC is an isotropic, high-resolution gradientbased technique that can quickly image a long section of the spine in a single, narrow, sagittal acquisition with multiplanar reconstructions, which we found to be ideal for identifying SCCMs, and thus we utilized this sequence in our screening spinal cord research MR imaging. When there is suspicion for CMs, using sensitive sequences in the spine and brain is necessary because the identification of a second $\mathrm{CM}$ changes the presumptive diagnosis from 
sporadic to genetic disease. This distinction has important implications for the individual, their family, and for genetic counseling.

Limitations of this study include the mix of clinically and incidentally discovered SCCMs in the baseline part of the study, the varied imaging techniques used for clinical and research imaging, and the limited collected clinical data. Also, because our cohort is patients with CCM1 and does not include patients with CCM2 and $C C M 3$, we are thus unable to extrapolate our results to patients with CCM2 and CCM3 familial CCM. Screening of the spinal cord as we did with our spinal cord research MR imaging by using only sagittal imaging would potentially be impractical in clinical practice where other spinal pathology may also be important to adequately image. However, if imaging is performed primarily to identify SCCMs, then performing a sequence sensitive to small foci of susceptibility as we did with our 3D MEDIC sequence, provides a highly sensitive evaluation.

\section{CONCLUSIONS}

SCCMs are a common feature of familial CCM syndrome. We have established an estimate of the prevalence of SCCMs in the familial CCM1 cohort at approximately 70\%. SCCMs can present clinically, including with hemorrhage, or can be found incidentally in these patients. Optimal technique, including gradientbased sequences such as 3D MEDIC, should be used for spinal cord imaging if SCCMs are suspected. This study supports the idea of familial CCM as progressive systemic disease that affects the entire central nervous system.

Disclosures: Marc Mabray—RELATED: Grant: NIH NINDS.* Jeffrey NelsonRELATED: Grant: NIH.* Atif Zafar-RELATED: Grant: National Institute of Health-National Institute of Neurological Disorders and Stroke, Comments: National Institute of Health-National Institute of Neurological Disorders and Stroke (grant number U54 NS065705), Radiology Department Seed Grant, and the Cody Unser First Step Foundation. UNRELATED: Employment: UNM Hospital. Helen Kim-RELATED: Grant: NIH*; UNRELATED: Consultancy: Recursion Pharmaceuticals, Comments: Consulting services for clinical advisory board; Grants/Grants Pending: NIH.* Leslie Morrison—RELATED: Grant: NINDS. Blaine Hart-RELATED: Grant: NIH.* *Money paid to institution.

\section{REFERENCES}

1. Zafar A, Quadri SA, Farooqui M, et al. Familial cerebral cavernous malformations. Stroke 2019;50:1294-301 CrossRef Medline

2. Akers A, Al-Shahi Salman R, Awad IA, et al. Synopsis of guidelines for the clinical management of cerebral cavernous malformations: Consensus recommendations based on systematic literature review by the Angioma Alliance Scientific Advisory Board Clinical Experts Panel. Neurosurgery 2017;80:665-80 CrossRef Medline

3. Zabramski JM, Wascher TM, Spetzler RF, et al. The natural history of familial cavernous malformations: results of an ongoing study. J Neurosurg 1994;80:422-32 CrossRef Medline

4. Morrison L, Akers A, et al. Cerebral Cavernous Malformation, Familial. In: Adam MP, Ardinger HH, Pagon RA, eds. GeneReviews ${ }^{\circledR}$. University of Washington, Seattle. 1993.

5. Al-Shahi Salman R, Berg MJ, Morrison L, et al. Hemorrhage from cavernous malformations of the brain: definition and reporting standards. Angioma Alliance Scientific Advisory Board. Stroke 2008;39:3222-30 CrossRef Medline

6. Flemming KD, Graff-Radford J, Aakre J, et al. Population-based prevalence of cerebral cavernous malformations in older adults:
Mayo Clinic Study of Aging. JAMA Neurol 2017;74:801-05 CrossRef Medline

7. Choquet H, Pawlikowska L, Lawton MT, et al. Genetics of cerebral cavernous malformations: current status and future prospects. $J$ Neurosurg Sci 2015;59:211-20 Medline

8. Plummer NW, Zawistowski JS, Marchuk DA. Genetics of cerebral cavernous malformations. Curr Neurol Neurosci Rep 2005;5:391-96 CrossRef Medline

9. Gunel M, Awad IA, Finberg K, et al. A founder mutation as a cause of cerebral cavernous malformation in hispanic Americans. $N \mathrm{Engl}$ J Med 1996;334:946-51 CrossRef Medline

10. Babu R, Owens TR, Karikari IO, et al. Spinal cavernous and capillary hemangiomas in adults. Spine 2013;38:E423-30 CrossRef Medline

11. Badhiwala JH, Farrokhyar F, Alhazzani W, et al. Surgical outcomes and natural history of intramedullary spinal cord cavernous malformations: a single-center series and meta-analysis of individual patient data: Clinic article. J Neurosurg Spine 2014;21:662-76 CrossRef Medline

12. Canavero S, Pagni CA, Duca S, et al. Spinal intramedullary cavernous angiomas: a literature meta-analysis. Surg Neurol 1994;41:381-88 CrossRef Medline

13. Choi GH, Kim KN, Lee S, et al. The clinical features and surgical outcomes of patients with intramedullary spinal cord cavernous malformations. Acta Neurochir (Wien) 2011;153:1677-84 CrossRef Medline

14. Gross BA, Du R, Popp AJ, et al. Intramedullary spinal cord cavernous malformations. Neurosurg Focus 2010;29:E14 CrossRef Medline

15. Goyal A, Rinaldo L, Alkhataybeh R, et al. Clinical presentation, natural history and outcomes of intramedullary spinal cord cavernous malformations. J Neurol Neurosurg Psychiatry 2019;90:695-703 CrossRef Medline

16. Nagoshi N, Tsuji O, Nakashima D, et al. Clinical outcomes and prognostic factors for cavernous hemangiomas of the spinal cord: a retrospective cohort study. J Neurosurg Spine 2019;31:271-78 CrossRef

17. Ren J, Hong T, He C, et al. Surgical approaches and long-term outcomes of intramedullary spinal cord cavernous malformations: a single-center consecutive series of 219 patients. J Neurosurg Spine 2019;31:123-32 CrossRef

18. Ren J, Hong T, Zeng G, et al. Characteristics and long-term outcome of $\mathbf{2 0}$ children with intramedullary spinal cord cavernous malformations. Neurosurgery 2019;nyz381 CrossRef

19. Ren J, Hong T, He C, et al. Coexistence of intracranial and spinal cord cavernous malformations predict aggressive clinical presentation. Front Neurol 2019;10:618 CrossRef Medline

20. Toldo I, Drigo P, Mammi I, et al. Vertebral and spinal cavernous angiomas associated with familial cerebral cavernous malformation. Surg Neurol 2009;71:167-71 CrossRef Medline

21. de Vos I, Vreeburg M, Koek GH, et al. Review of familial cerebral cavernous malformations and report of seven additional families. Am J Med Genet A 2017;173:338-51 CrossRef Medline

22. Tandberg SR, Bocklage T, Bartlett MR, et al. Vertebral intraosseous vascular malformations in a familial cerebral cavernous malformation population: prevalence, histologic features, and associations with CNS disease. AJR Am J Roentgenol 2020;214:428-36 CrossRef Medline

23. de Souza JM, Domingues RC, Cruz LCH, et al. Susceptibilityweighted imaging for the evaluation of patients with familial cerebral cavernous malformations: a comparison with $\mathrm{T} 2$-weighted fast spin-echo and gradient-echo sequences. AJNR Am J Neuroradiol 2008;29:154-58 CrossRef Medline

24. Sparacia G, Speciale C, Banco A, et al. Accuracy of SWI sequences compared to $\mathrm{T} 2{ }^{*}$-weighted gradient echo sequences in the detection of cerebral cavernous malformations in the familial form. Neuroradiol J 2016;29:326-35 CrossRef 